\title{
Gliptin evidence to fight SARS-CoV-2 infection
}

\begin{abstract}
People with diabetes represent a population at greater risk of infection and complications from SARS-CoV-2. Diabetes represents one of the most important comorbidities related to the severity of viral infection causing an increased risk of serious complications such as severe acute respiratory syndrome and multiorgan dysfunction associated with a hyperinflammatory state. Glycaemic normalization in patients with diabetes must be managed in the best possible way even during SARS-CoV-2 infection to avoid serious complications. However, for some antidiabetic agents such as DPP-4 inhibitors (gliptins), there is evidence of efficacy against SARS-CoV-2 extrapancreatic glycaemic normalization. The objective of this article is to provide an overview of current evidence on the potential therapeutic benefits of gliptins to combat SARS-CoV-2 infection. (Clin Diabetol 2021; 10; 5: 383-385)
\end{abstract}

Key words: gliptins, diabetes, SARS-CoV-2, infection, virology

\section{Introduction}

\section{SARS-CoV-2 infection and diabetes}

The global pandemic caused by the new SARSCoV-2 began in China in November 2019 and quickly became a global problem, representing a health emergency. To date, about 6.15 million positive cases and 372,000 deaths have been recorded with over 260 countries affected $[1,2]$ SARS-CoV-2 infection can range

Address for correspondence:

Francesco Ferrara

Hospital Pharmacist Manager

Pharmaceutical department, UsI Umbria 1

A. Migliorati street, 06132, Perugia, Italy

e-mail: francesco.ferrara@uslumbria1.it

Clinical Diabetology 2021, 10; 5: 383-385

DOI: $10.5603 /$ DK.2021.0050

Received: 4.02.2021

Accepted: 14.09.2021 from asymptomatic or slightly symptomatic to more severe stages such as multi-organ dysfunction resulting in fatal lung injury and thrombus formation. Studies show that people with pre-existing chronic diseases such as diabetes are at increased risk of infection and serious complications. To date, there are no direct antivirals and effective vaccines against SARS-CoV-2 [3-5]. During the current global SARS-CoV-2 pandemic, diabetes has been identified as an important risk factor for the development of severe SARS-CoV-2 viral pneumonia [6].

Epidemiological data indicate that the risk of a fatal outcome caused by SARS-CoV- 2 infection is up to $50 \%$ higher in patients with diabetes [7]. Many factors may increase the risk of serious complications for the patients with diabetes and SARS-CoV-2 such as the presence of a deficient immune system, an inadequate fibrinolytic cascade, an overactive inflammatory state, and secondary cardiovascular disease caused by diabetes [8]. In addition, it should be considered that the SARS-CoV-2 virus uses the angiotensin 2 conversion enzyme protein (ACE2) to penetrate the epithelial cells of the lung. ACE2 has a protective role especially concerning inflammation of the respiratory tract. SARSCoV-2 infection in the most severe stages reduces the expression of ACE2, this is one of the causes of hyper inflammation and respiratory failure $[9,10]$, moreover, diabetes also changes the expression of ACE2, and this can cause an even more complicated and serious clinical situation. Finally, the viral infection itself can cause a worsening of the diabetes disease with a more difficult glycaemia to control [11-18]. A fundamental aspect to highlight is that the DPP-4 protein (therapeutic target of gliptins) has been identified as a functional receptor for the virus responsible for MERS [19], a virus similar to that of SARS-CoV-2, to date, it is not certain that it is also a functional receptor for SARS-CoV-2, investigations in this direction are underway. Moreover, diabetes patients have an altered expression of the DPP-4 protein, this factor may contribute to overactive 
inflammation, which could further complicate the clinical situation. Based on the considerations expressed, it emerges that the management of the patient with diabetes and SARS-CoV-2 positive is extremely delicate. The recommendations indicate that drug treatment for diabetes should not be discontinued during viral infection if there are no particular contraindications, however, for some antidiabetic drugs such as gliptins, there is evidence in the literature showing their potential additional therapeutic role against SARS-CoV-2 infection.

\section{Gliptins' agents and potential efficacy against SARS-CoV-2}

Gliptins (sitagliptin, vildagliptin, etc.) are DPP-4 inhibitors with undoubted therapeutic efficacy in the anti-diabetes field. Recently for this class of drugs evidence has shown extrapancreatic pleiotropic activity of glycaemic normalization. The DPP-4 protein has several actions, in particular, it plays an important role in the regulation of the immune system by activating $T$ cells and regulating CD86 expression and is responsible for increasing inflammation in patients with diabetes. It should also be noted that the activity of DPP-4 can influence the function of several cytokines, chemokines, and growth factors. Some studies have suggested that a higher mortality rate and complications in people with diabetes and MERS infected may be associated with a dysregulated immune response mediated by the DPP-4 protein $[20,21]$, so a potential therapeutic role of gliptins in fighting SARS-CoV-2 infection is also to be assumed. However, to date, the effects of DPP-4 inhibition on the immune system and inflammation are still not fully understood.

A meta-analysis has shown that upper respiratory tract infections do not increase significantly with the inhibitory treatment of DPP-4 [22], moreover, MERSCoV uses DPP-4 to enter host cells [23], but it is not known whether SARS-CoV-2 uses the same protein to enter the cell as well, in addition to ACE-2, If this were demonstrated, the use of gliptin could decrease the risk of SARS-CoV-2 infection, but for now it is only a hypothesis. The potential benefit in the treatment of SARS-CoV-2 infection with DPP-IV inhibitors remains to be investigated. To date, it is not entirely clear whether DPP-IV inhibition may play an important role in controlling inflammation in patients with diabetes and SARS-CoV-2, but it may be a potential target to prevent and reduce the risk and progression of acute airway complications that a patient with diabetes may have in addition to SARS-CoV-2 infection [24]. Interesting new developments in this field may be represented by telemedicine which, in diabetes, promises to make new therapeutic options more effective and safer [25].

\section{Conclusions}

The SARS-CoV-2 global pandemic represents one of the greatest health challenges in the history of mankind. Patients with comorbidities such as diabetes may be at greater risk of complications if infected with SARS-CoV-2. Treatment of diabetes in a patient with SARS-CoV-2 must be carefully managed, for some antidiabetic agents such as gliptins, there is evidence of extrapancreatic pleiotropic effects and glycaemic normalization, which could be an added value in the fight against SARS-CoV-2 infection in the patient with diabetes.

\section{Conflicts of interest \\ None.}

\section{REFERENCES}

1. World Health Organization HO (2020) Coronavirus disease 2019 (COVID-19) situation report. https://www.who.int/emergencies/ diseases/novel-coronavirus-2019/situation-reports.

2. Vitiello A, Ferrara F, Pelliccia $C$, et al. Cytokine storm and colchicine potential role fighting SARS-CoV-2 pneumonia. Italian Journal of Medicine. 2020; 14(2): 88-94, doi: 10.4081/itjm.2020.1284.

3. Lin L, Lu L, Cao W, et al. Hypothesis for potential pathogenesis of SARS-CoV-2 infection-a review of immune changes in patients with viral pneumonia. Emerg Microbes Infect. 2020; 9(1): 727-732, doi: 10.1080/22221751.2020.1746199, indexed in Pubmed: 32196410.

4. Ferrara F, Granata G, Pelliccia C, et al. The added value of pirfenidone to fight inflammation and fibrotic state induced by SARSCoV-2 : Anti-inflammatory and anti-fibrotic therapy could solve the lung complications of the infection? Eur J Clin Pharmacol. 2020; 76(11): 1615-1618, doi: 10.1007/s00228-020-02947-4, indexed in Pubmed: 32594204.

5. Vitiello A, Ferrara F. Correlation between renin-angiotensin system and Severe Acute Respiratory Syndrome Coronavirus 2 infection: What do we know? Eur J Pharmacol. 2020; 883: 173373, doi: 10.1016/j.ejphar.2020.173373, indexed in Pubmed: 32679185.

6. Zou $Q$, Zheng $S$, Wang $X$, et al. Influenza A-associated severe pneumonia in hospitalized patients: Risk factors and NAI treatments. Int J Infect Dis. 2020; 92: 208-213, doi: 10.1016/j. ijid.2020.01.017, indexed in Pubmed: 31978583.

7. Remuzzi A, Remuzzi G. COVID-19 and Italy: what next? The Lancet. 2020; 395(10231): 1225-1228, doi: 10.1016/s01406736(20)30627-9.

8. Bornstein SR, Rubino F, Khunti K, et al. Practical recommendations for the management of diabetes in patients with COVID-19 Lancet Diabetes Endocrinol. Lancet Diabetes Endocrinol. 2020(8): 546-550, doi: doi.org/10.1016/ S2213-8587(20)30152-2.

9. Hoffmann M, Kleine-Weber H, Schroeder S, et al. SARS-CoV-2 Cell Entry Depends on ACE2 and TMPRSS2 and Is Blocked by a Clinically Proven Protease Inhibitor. Cell. 2020; 181(2): 271-280. e8, doi: 10.1016/j.cell.2020.02.052.

10. Bindom SM, Lazartigues $E$. The sweeter side of ACE2: physiological evidence for a role in diabetes. Mol Cell Endocrinol. 2009; 302(2): 193-202, doi: 10.1016/j.mce.2008.09.020, indexed in Pubmed: 18948167.

11. Yang JK, Lin SS, Ji XJ, et al. Binding of SARS coronavirus to its receptor damages islets and causes acute diabetes. Acta Diabetol. 
2010; 47(3): 193-199, doi: 10.1007/s00592-009-0109-4, indexed in Pubmed: 19333547.

12. Vitiello A, Ferrara F. Therapeutic Strategies for SARS-CoV-2 acting on ACE-2. Eur J Pharm Sci. 2021; 156: 105579, doi: 10.1016/j. ejps.2020.105579, indexed in Pubmed: 33010419.

13. Vitiello A, Ferrara F. Pharmacological agents to therapeutic treatment of cardiac injury caused by Covid-19. Life Sci. 2020; 262: 118510, doi: 10.1016/j.Ifs.2020.118510, indexed in Pubmed: 32991879.

14. Ferrara F. Anti-rheumatic in SARS-CoV-2: benefit or risk? Italian Journal of Medicine. 2020, doi: 10.4081/itjm.2020.1290.

15. Ferrara F, Porta RLa, D'Aiuto V, et al. Remdesivir and COVID-19. Ir J Med Sci. 2020 [Epub ahead of print], doi: 10.1007/s11845020-02401-5, indexed in Pubmed: 33068241.

16. Vitiello A, Ferrara F, Porta RLa. Remdesivir and COVID-19 infection, therapeutic benefits or unnecessary risks? Ir J Med Sci. 2021 [Epub ahead of print], doi: 10.1007/s11845-020-02482-2, indexed in Pubmed: 33433843

17. Vitiello A, Ferrara F. Remdesivir versus ritonavir/lopinavir in COVID-19 patients. Ir J Med Sci. 2020 [Epub ahead of print], doi: 10.1007/s11845-020-02440-y, indexed in Pubmed: 33206336.

18. Ferrara F, Porta RLa, Santilli P, et al. Are multiple sclerosis therapies safe in severe acute respiratory syndrome coronavirus 2 times? Indian J Pharmacol. 2020; 52(5): 441-442, doi: 10.4103/ijp. IJP_417_20, indexed in Pubmed: 33283779.
19. Raj V, Mou H, Smits S, et al. Dipeptidyl peptidase 4 is a functional receptor for the emerging human coronavirus-EMC. Nature. 2013; 495(7440): 251-254, doi: 10.1038/nature12005.

20. Li K, Wohlford-Lenane CL, Channappanavar R, et al. Mouseadapted MERS coronavirus causes lethal lung disease in human DPP4 knockin mice. Proc Natl Acad Sci U S A. 2017; 114(15): E3119-E3128, doi: 10.1073/pnas.1619109114, indexed in Pubmed: 28348219.

21. Fan C, Wu Xi, Liu Q, et al. A Human DPP4-Knockin Mouse's Susceptibility to Infection by Authentic and Pseudotyped MERSCoV. Viruses. 2018; 10(9), doi: 10.3390/v10090448, indexed in Pubmed: 30142928.

22. Yang W, Cai X, Han X, et al. DPP-4 inhibitors and risk of infections: a meta-analysis of randomized controlled trials. Diabetes Metab Res Rev. 2016; 32(4): 391-404, doi: 10.1002/dmrr.2723, indexed in Pubmed: 26417956.

23. Raj V, Mou H, Smits S, et al. Dipeptidyl peptidase 4 is a functional receptor for the emerging human coronavirus-EMC. Nature. 2013; 495(7440): 251-254, doi: 10.1038/nature12005.

24. lacobellis G. COVID-19 and diabetes: Can DPP4 inhibition play a role? Diabetes Res Clin Pract. 2020; 162: 108125, doi: 10.1016/j. diabres.2020.108125, indexed in Pubmed: 32224164.

25. Klonoff DC. The Coronavirus 2019 Pandemic and Diabetes: An International Perspective. J Diabetes Sci Technol. 2020; 14(4): 703-704, doi: 10.1177/1932296820933075, indexed in Pubmed: 32517506. 